\title{
METALLIFEROUS SEDIMENTS AND THE SCAVENGING RESIDENCE TIME OF Nd
} NEAR HYDROTHERMAL VENTS

\author{
Alex N. Halliday ${ }^{1}$, Jon P. Davidson ${ }^{2}$, Peter Holden ${ }^{2}$, Robert M. Owen ${ }^{1}$ and Annette M. Olivarez ${ }^{3}$
}

\begin{abstract}
The isotopic composition of Nd is uniform in metalliferous sediments formed at distances varying from $>1000 \mathrm{~km}$ to within $10 \mathrm{~km}$ of the East Pacific Rise (EPR) palaeoridge. These data indicate that hydrothermal vent fluids, despite having concentrations more than 500 times greater, have no effect on the $\mathrm{Nd}$ isotopic composition of seawater. This implicates efficient scavenging of bydrothermal Nd by particulates, resulting in extremely short residence times ( $<1$ year) close to the hydrothermal vents. Therefore Nd isotopic studies of ancient seawater precipitates, particularly metalliferous sediments, cannot be used to delimit the magnitude of past hydrothermal circulation without independent constraints on local scavenging rates (or residence times) relative to those of modern oceans.
\end{abstract}

\section{Introduction}

Estimates of the magnitude of hydrothermal fluxes in ancient oceans have been based in part on the Nd isotopic compositions of chemical sediments such as banded iron formations [Jacobsen and Pimental-Klose, 1988; Derry and Jacobsen, 1988]. It has been observed that the initial $\varepsilon N d$ of such early metalliferous sediments is relatively high. This has lead to the conclusion that Nd derived from oceanic crust was more important in the past because of higher hydrothermal fluxes. Modern metalliferous sediments are Fe-rich pelagic deposits formed by precipitation from hydrothermal plumes emanating from vents near ocean ridges such as the East Pacific Rise. They form one of the largest repositories of REE-rich particulates on the ocean floor and are deposited as the hydrothermal plume is wafted away from the ridge by ocean currents. In a recent isotopic study the variable influence of ocean ridge-derived hydrothermal $\mathrm{Pb}$ on such metalliferous sediment was demonstrated [Barrett et al., 1987]. White et al. [1986] also showed that there was a MORB-like component of $\mathrm{Hf}$ in seawater. In contrast, the isotopic composition of Nd in seawater has been shown to be regionally variable and to reflect the local continental crustal provenance of the rare earth elements (REEs), rather than hydrothermal components [Piepgras et al., 1979; Piepgras and Wasserburg, 1980, 1985; Goldstein and O'Nions, 1981; Palmer and Elderfield, 1985;

\footnotetext{
${ }^{\mathrm{l}}$ Department of Geological Sciences, University of Michigan,

${ }^{2}$ Department of Earth \& Space Sciences, University of California at Los Angeles,

${ }^{3}$ Department of Earth Sciences, University of Notre Dame
}

Copyright 1992 by the American Geophysical Union.

Paper number 92GL00393

0094-8534/92/92GL-00393\$03.00
Piepgras and Jacobsen, 1988]. This is because particulate scavenging [Ruhlin and Owen, 1986; Klinkhammer et al., 1983; Owen and Olivarez, 1988; Olivarez and Owen, 1989; German et al., 1990] results in short residence times compared with the mixing times of the ocean. Goldstein and Jacobsen [1987] utilized the $\mathrm{Nd}$ and $\mathrm{Sr}$ isotopic compositions of river waters and the oceans to show that the present hydrothermal flux of Nd to the oceans must be small (<5\%), and obtained a residence time for $\mathrm{Nd}$ in seawater of 7100 years [Goldstein and Jacobsen, 1988]. Here we show that the isotopic composition of $\mathrm{Nd}$ in metalliferous sediments from near the East Pacific Rise is totally unaffected by hydrothermal inputs. This is because of the importance of scavenging which prevents hydrothermal Nd from mixing with seawater on anything other than a local scale close to the vents. As such Nd isotopic compositions cannot be used to infer ancient hydrothermal fluxes without independent constraints on the extent of scavenging.

\section{Sampling and analytical approaches}

The metalliferous sediments in DSDP core from Leg 92 (site 598), located to the west of the East Pacific Rise (19\%) represent a complete record of hydrothermal sedimentation at the flank of the East Pacific Rise over the last 16 Myrs. They are ideal for studying because of the absence of continentderived detritus and lack of organic diagenetic remobilization of Fe and Mn [Ruhlin and Owen, 1986]. The lack of diagenetic modification is indicated by porewater $\mathrm{Mn}$ analyses and comparison of downcore $\mathrm{Mn} / \mathrm{Fe}$ ratios with those of modem hydrothermal precipitates that originated from EPR vent fluids. Ruhlin and Owen [1986] showed that the REE concentration and $\Sigma R E E / F e$ ratio at this site decrease with increasing depth downcore and therefore increasing age of these sediments. This can be related to proximity of the ridge; the youngest sediments were formed $1139 \mathrm{~km}$ from the palaeoridge whereas the oldest (deepest) sediments were formed only $9 \mathrm{~km}$ from the palaeoridge. The concentration of REEs in particulates might then be expected to increase as a result of scavenging from seawater, in proportion to the distance travelled by the hydrothermal plume from the ridge [Ruhlin and Owen, 1986]. A plot of rare earth element concentrations versus distance from palaeoridge axis displayed a break of slope at the age at which the sediments passed through the palaeolysocline suggesting that the concentrations were also affected by postdepositional scavenging at the seawater/sediment interface [Ruhlin and Owen, 1986]. The variations in REE concentration could then also reflect a decrease in burial rate with distance from the ridge.

Six representative samples from DSDP Leg 92, site 598, covering the range in ages and paleodistance $(9-1085 \mathrm{~km})$ were selected for Nd isotopic analysis. Detailed descriptions of the samples can be found elsewhere [Ruhlin and Owen, 
1986]. The sediments are composed almost entirely of mixtures of carbonates and metalliferous (hydr)oxides, the latter representing the overwhelmingly dominant repository of Nd. Attempts were made to isolate these components utilizing sequential leaching experiments as detailed in Table 1. In the first experiment the bulk sediments were analyzed with no preparation. In the second experiment the samples were leached with hydrochloric acid, and the leachate and residue analyzed. The hydrochloric acid leach should dissolve carbonates, but is also expected to dissolve a large amount of the metalliferous oxides. For the third experiment two samples (oldest and youngest) were leached successively with water, acetic acid and hydrochloric acid to match the preparation used by Barrett et al. [1987] for $\mathrm{Pb}$ isotopic studies of sediments from the same site. The water is expected to dissolve only highly soluble phases (such as $\mathrm{NaCl}$ ), whereas most carbonates will be soluble in acetic acid. The $\mathrm{HCl}$ acid is expected to dissolve the main metalliferous (hydr)oxide phases. The small amount of residue in all these experiments (dissolved in hydrofluoric, perchloric and nitric acids) is expected to be a mixture of minor silicates and organic compounds.

\section{$\mathrm{Nd}$ isotopic compositions of metalliferous sediments}

The Nd isotopic compositions of each of the leachates and residues are presented in Table 1. Metalliferous oxidedominated Nd isotopic compositions are to be expected from the bulk sediments and all the hydrochloric acid leachates. These leachates have the same, or higher ${ }^{143} \mathrm{Nd} /{ }^{144} \mathrm{Nd}$ than the bulk sediment (Figure 1a). Similarly the bulk sediment has the same or slightly higher ${ }^{143} \mathrm{Nd} /{ }^{144} \mathrm{Nd}$ than the residue. The residues (with relatively unradiogenic $\mathrm{Nd}$ ) could represent a small component of atmospheric particulates. However these variations are trivial and the $\mathrm{Nd}$ isotopic compositions are effectively uniform, with no sign of a greater MORB contribution in older samples deposited closer to the paleoridge (Figure 1b). The Nd isotopic compositions are more uniform and lower $(\varepsilon N d=-5.2$ to -4.4) than the range for Pacific authigenic sediments reported by Piepgras et al. [1979] $(\varepsilon N d=-4.4$ to -0.2$)$. The higher values reported by Piepgras et al. were for metalliferous sediments and hydrothermal crusts. Comparable data were obtained O'Nions et al. [1978] and Goldstein and O'Nions [1981].

The uniform $\mathrm{Nd}$ isotopic compositions cannot reflect late alteration of metalliferous oxides in the sediment pile. First, there is no evidence of REE enrichment with depth, as might be expected if the Nd isotopic compositions were due to late adsorption of REEs from downward penetrating fluids. The ¿REEs decreases dramatically with depth, age and proximity to the paleoridge [Ruhlin and Owen, 1986]. Second, the $\mathrm{Fe} / \mathrm{Mn}$ ratios and organic carbon concentrations, which are very sensitive to diagenesis, are clearly well preserved [Olivarez and Owen, 1989]. Third, the oldest samples have the lowest REE concentration and should have suffered the most extensive alteration. Yet these have the most pronounced positive Eu anomalies relative to seawater [Høgdahl et al., 1968] indicating the preservation of a significant hydrothermal component [Ruhlin and Owen,

TABLE 1. ${ }^{143} \mathrm{Nd} /{ }^{144} \mathrm{Nd}$ ratios of DSDP sediments from site 598

\begin{tabular}{lllllll}
\hline Sample number & 1 & 2 & 3 & 4 & 5 & 6 \\
\hline DSDP number & $1 / 1-46 / 48$ & $1 / 3-88 / 90$ & $2 / 4-28 / 30$ & $3 / 13-18 / 20$ & $4 / 6-19 / 21$ & $5 / 6-58 / 60$ \\
Age (Ma) & 0.47 & 3.89 & 8.74 & 12.3 & 14.6 & 15.9 \\
Distance from paleoridge (km) & 1085 & 802 & 450 & 227 & 85 & 9 \\
Nd ppm & 155 & 229 & 95 & 70 & 66 & 54 \\
(1) Bulk sediment & $0.512373 \pm 7$ & $0.512380 \pm 8$ & $0.512426 \pm 9$ & $0.512409 \pm 8$ & $0.512418 \pm 7$ & $0.512390 \pm 6$ \\
(2) Hydrochloric acid leach & $0.512389 \pm 8$ & $0.512429 \pm 7$ & -- & $0.512451 \pm 8$ & $0.512435 \pm 7$ & $0.512402 \pm 24$ \\
(2) Residue & $0.512384 \pm 11$ & $0.512365 \pm 13$ & $0.512377 \pm 13$ & - & $0.512421 \pm 23$ & - \\
(3) Water leach & $0.512377 \pm 15$ & -- & -- & - & -- & - \\
(3) Acetic acid leach & $0.512379 \pm 9$ & - & -- & - & -- & $0.512387 \pm 9$ \\
(3) Hydrochloric acid leach & $0.512411 \pm 12$ & - & -- & - & - & $0.512390 \pm 10$ \\
(3) Residue & $0.512372 \pm 12$ & - & -- & -- & -- & $0.512360 \pm 12$ \\
\hline
\end{tabular}

All data obtained at the Radiogenic Isotope Geochemistry Laboratory at the University of Michigan, using standard ion exchange separation techniques and a VG Sector moulticollector mass spectrometer, as described elsewhere (Halliday et al., 1989). The average value of ${ }^{143} \mathrm{Nd} /{ }^{144} \mathrm{Nd}$ for the La Jolla Nd standard was $0.511855 \pm 8(2 \sigma$ mean, $n=18)$. Numbers in parentheses denote separate experiments (see text). For the detailed leaching experiment (3) on samples 1 and 6 , the following procedure was adopted. The powdered sample was slurried in pure deionized $\mathrm{H}_{2} \mathrm{O}$ and left for $\mathrm{c} .18$ hours, warmed for $1 / 2$ hour and filtered. The filtrate (containing water-soluble components such as salt), was centrifuged and any precipitate which had circurnvented the filtration process was discarded. It was then evaporated and taken up in $1 \mathrm{ml}$ of $2.5 \mathrm{~N} \mathrm{HCl}$, and analyzed for ${ }^{143} \mathrm{Nd} /{ }^{144} \mathrm{Nd}$ following standard ion exchange separation. The residue was rinsed from the filter paper into a beaker, evaporated to dryness, and 10\% distilled acetic acid added. This should have resulted in the dissolution of most carbonate. The leachate and residve were again separated by filtration and the leachate analyzed. The residue was evaporated to dryness, then leached with $10 \%$ distilled $\mathrm{HCl}$ for 2 hours. Leachate and residue were separated as before and the HCl-soluble component analyzed. Following evaporation, total dissolution of the remaining residue was achieved using $\mathrm{HF}, \mathrm{HNO}_{3}$ and $\mathrm{HClO}_{4}$. This fraction was then analyzed. 


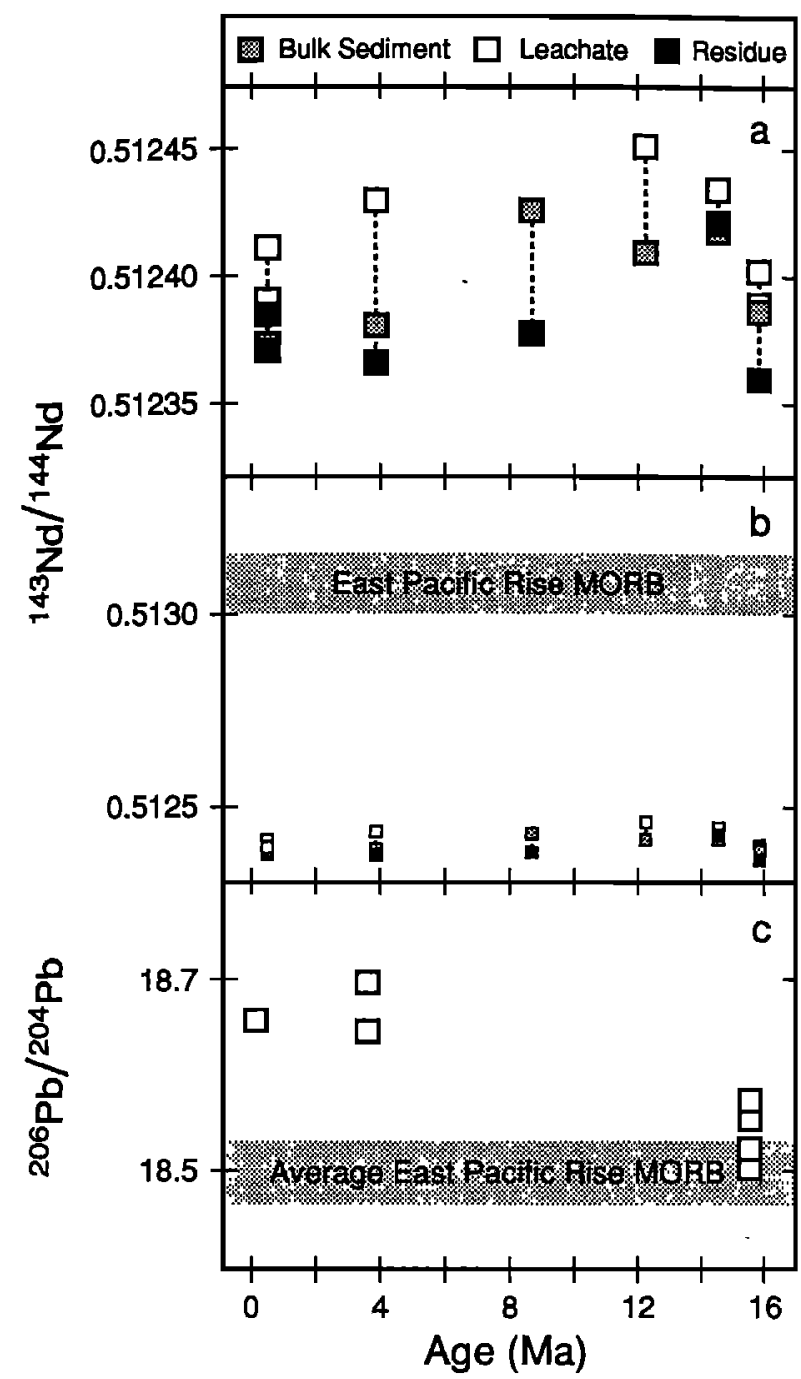

Fig. 1. Variation in isotopic compositions of metalliferous sediments from DSDP Leg 92, Site 598, located to the west of the East Pacific Rise ( $\left.19^{\circ} \mathrm{S}\right)$, as a function of age. a) ${ }^{143} \mathrm{Nd} /{ }^{144} \mathrm{Nd}$ of bulk sediments, metalliferous oxide leachates, and leachate residues. b) data shown in (a) relative to field for East Pacific Rise basalts [White et al., 1987]. c) $\mathrm{Pb}$ isotopic data of Barrett et al. [1987] for metalliferous oxide leachates relative to field for East Pacific Rise basalts [White et al., 1987].

1986], consistent with their original deposition site, closest to the paleoridge. Last, major element studies of pore waters suggest a minor amount of carbonate dissolution; otherwise no significant post-depositional effects.

The results for $\mathrm{Nd}$ contrast with those for $\mathrm{Pb}$ [Barrett et al, 1987], which show a clear MORB component over all Leg 92 sites, which increases with proximity to the vents (Figure 1c). This is not surprising in view of the fact that ocean floor hydrothermal solutions may contain up to 2,000 ppm Pb [Vidal and Clauer, 1981; Brevart et al., 1981] but less than 0.01 ppm Nd [Hinkley and Tatsumoto, 1987]. Nevertheless, the hydrothermal component should still be detectable in the $\mathrm{Nd}$ isotopic compositions if they contribute as little as $3 \%$ of the $\mathrm{Nd}$. The concentrations of $\mathrm{Nd}$ in vent fluids relative to seawater typically lie in the range $6-100$
[Michard et al, 1983; Piepgras and Wasserburg, 1985; Michard and Albarède, 1986; Hinkley and Tatsumoto, 1987], the variability reflecting dilution with seawater, and interaction and scavenging en route to the sampling site. Given the extremely low concentrations of Nd in seawa'ter $\left(<10^{-5} \mathrm{ppm}\right)$ [Høgdahl, 1968], compared with concentrations 500 times higher in projected endmember EPR vent fluids [Hinkley and Tatsumoto, 1987], the ratio of vent fluid to seawater needs to be $<0.001$, even at a distance as close as 9 $\mathrm{km}$ from the paleoridge, unless $\mathrm{Nd}$ is being very efficiently removed by scavenging close to the vents.

A rough independent estimate of the amount of vent fluid relative to seawater in the vertical section overlying the paleosediment surface can be obtained from $\mathrm{Mn} / \mathrm{Nd}$ ratios in the sediments. The $\mathrm{Mn}$ in the metalliferous sediment is derived wholly from the hydrothermal component since the $\mathrm{Mn}$ enrichment in the plume relative to seawater is $10^{6}$. The isotopic data presented here indicate that the $\mathrm{Nd}$ is derived entirely from seawater. The ratio of $\mathrm{Nd}$ in seawater to $\mathrm{Mn}$ in hydrothermal vent fluids is roughly $7 \times 10^{-5}$ [German et al., 1990; Von Damm et al., 1985]. The sediment deposited 9 $\mathrm{km}$ from the ridge has a $\mathrm{Mr} / \mathrm{Nd}$ ratio of 5400 [Ruhlin and Owen, 1986]. Ignoring differential scavenging, the product of these two figures (0.4) gives an order of magnitude value for the hydrothermal fluid/seawater ratio at this distance. The average seawater residence time of $\mathrm{Nd}$ was determined by Goldstein and Jacobsen [Goldstein and Jacobsen, 1988] at 7100 years. This is considerably in excess of the scavenging residence time of $\mathrm{Mn}$ in a hydrothermal plume determined by Weiss [1977] at 50 years. However the only way for the hydrothermal fluid/seawater ratio of $<0.001$ calculated using the Nd isotopic data to be reconciled with that calculated using $\mathrm{Mn} / \mathrm{Nd}$ ratios is for the scavenging residence time of $\mathrm{Nd}$ to be less than 50 years. Post-depositional scavenging of Nd would not affect this conclusion, and the data implicate rapid scavenging near the vents, effectively removing the hydrothermal component of $\mathrm{Nd}$ such that there is no contribution to the metalliferous sediments. Application of models quantifying trace element scavenging in terms of residence time relative to dispersal rate in the oceans [Weiss, 1977; Craig, 1974] indicates that localized residence times for hydrothermal $\mathrm{Nd}$ from the plume have to be extremely short ( $<1$ year) to achieve even a factor of 2 reduction in concentration within $10 \mathrm{kms}$ of the vents. The most likely explanation of such rapid scavenging is that $\mathrm{Nd}$ is removed instantaneously at hydrothermal vents, presumably by absorption on the surfaces of the large volumes of dense particulates produced in and around the plumes [Olivarez and Owen, 1989; German et al., 1990].

Hydrothermal $\mathrm{Nd}$ is not incorporated to any great extent in ocean circulation at the present time, as predicted by Piepgras and Wasserburg [1980] and Goldstein and Jacobs sen [1987]. It is for the same reason that the REE pattern of seawater shows only localized minor evidence of enhanced Eu relating to the positive Eu anomaly in hydrothermal r vent fluids [Goldstein and Jacobsen, 1988]. Similarly, hydrothermal fluxes are better estimated by mass balarıcing the $\mathrm{Sr}$ rather than Nd isotopic compositions of seawater and continental runoff [Goldstein and Jacobsen, 1987].

Increased hydrothermal ridge fluxes will probabliy not change this scenario since it is the hydrothermal particulates 
themselves that are causing the scavenging [Owen and Olivarez, 1988, 1989]. The greater the contribution of hydrothermal particulates the more efficient the scavenging and the less hydrothermal $\mathrm{Nd}$ enters the oceans. The $\mathrm{Nd}$ isotopic compositions of metalliferous sediments ancient and modern are therefore an ineffective monitor of the intensity of ocean floor hydrothermal activity. The extent to which the Nd isotopic composition of a metalliferous sediment indicates the importance or otherwise of hydrothermal fluxes will clearly depend on proximity of the plume source, the plume velocity and residence times. REE residence times are a function of scavenging, which is dependent on ocean chemistry. Hence use of Nd isotopic compositions of chemical sediments for studying paleogeography of continental land masses could yield ambiguous results for the Precambrian, since REE residence times may have been longer because of greater solubility of $\mathrm{Fe}$ in the early oceans. It is therefore critical to understand the relative importance of scavenging in the geological past, and to document the isotopic composition of $\mathrm{Nd}$ in the continental sources exposed at the time in question, before the $\mathrm{Nd}$ isotopic compositions of Precambrian banded iron formations in particular, can be utilized to indicate the magnitude of ancient hydrothermal fluxes [Jacobsen and Pimental-Klose, 1988].

Acknowledgements. This research was supported from National Science Foundation, Michigan Memorial Phoenix Project and Tumer Fund grants to ANH, for isotopic studies of hydrothermal processes. ANH thanks Klaus Mezger, Charlie DeWolf and Gareth Davies for criticism of the script and, or, discussion.

\section{References}

Barrett, T.J., Taylor, P.N. and Lugowski, J. Geochim. Cosmochim. Acta, 51, 2241-2253 1987.

Brevart, O., Dupre, B. and Allègre, C.J. Econ. Geol., 76, 1205-1210, 1981.

Craig, H. Earth Planet. Sci. Lett., 23, 149-159 1974.

Derry, L.A. and Jacobsen, S.B. Geophys. Res. Lett., 15, 397 4001988.

German, C.R. Klinkhammer, G.P., Edmond, J.M., Mitra, A. and Elderfield, H. Nature, 345, 516-518 1990.

Goldstein, S.J. and Jacobsen, S.B. Chem. Geol. 66, 245-272 1987.

Goldstein, S.J. and Jacobsen, S.B. Earth Planet. Sci. Lett., 89, 35-47 1988.

Goldstein, S.L. and O'Nions, R.K. Nature, 292, 324-327 1981.

H, xgdahl, O.T., Melson, S. and Bowen, V.T. Adv. Chem. Ser., 73, 308-3251968.
Halliday, A.N., Mahood, G., Holden, P., Metz, J.M., Dempster, T.J. and Davidson, J.P. Earth Planet. Sci. Lett. 94, 274-2901989.

Hinkley, T.K. and Tatsumoto, M. Jl. Geophys. Res., 92, 11,400-11,410 1987.

Jacobsen, S.B. and Pimental-Klose, M.R. Earth Planet. Sci. Lett., 87, 29-44 1988.

Klinkhammer, G., Elderfield, H. and Hudson, A. Nature, 305, 185-188 1983.

Michard, A., Albarède, F., Michard, G., Minster, J.-F. and Charlous, J.-L. Nature, 303, 795-797 1983.

Michard, A. and Albarède. Chem. Geol., 55, 51-60 1986.

Olivarez, A.M. and Owen, R.M. Geochim. Cosmochim. Acta, 53, 757-762 1989.

O'Nions, R.K., Carter, S.R., Cohen, R.S., Evensen, N.M. and Hamilton, P.J. Nature, 273, 435-438 1978.

Owen, R.M. and Olivarez, A.M. Mar. Chem., 25, 183-196 1988.

Palmer, M.R. and Elderfield, H. Earth Planet. Sci. Lett., 73, 299-305 1985.

Piepgras, D.J. and Jacobsen, S.B. Geochim. Cosmochim. Acta, 52, 1373-1381 1988.

Piepgras, D.J. and Wasserburg, G.J. Earth Planet. Sci. Lett., 50, 128-1381980.

Piepgras, D.J. and Wasserburg, G.J. Earth Planet. Sci. Lett., 72, 341-356 1985.

Piepgras, D.J., Wasserburg, G.J., and Dasch, E.J. Earth Planet. Sci.Lett., 45, 223-236 1979.

Ruhlin, D.E. and Owen, R.M. Geochim. Cosmochim. Acta, 50, 393-400 1986.

Vidal, P. and Clauer, N. Earth Planet. Sci. Lett., 55, 237-246 1981.

Von Damm, K.L., Edmond, J.M., Grant, B., Measures, C.I., Walden, B. and Weiss, R.F. Geochim. Cosmochim. Acto, 49, 2197-2220 1985.

Weiss, R.F. Earth Planet. Sci. Lett., 37, 257-262 1977.

White, W.M., Hofmann, A.W. and Puchelt, H. Jl. Geophys. Res., 92, 4881-4893 1987.

White, W.M., Patchett, J. and Ben Othman, D. Earth Planet. Sci. Lett., 79, 46-54 1986.

A.N. Halliday and R.M. Owen, Department of Geological Sciences, University of Michigan, Ann Arbor, MI 48109-1063.

J.P Davidson and P. Holden, Department of Earth \& Space Sciences, University of California, Los Angeles, CA 90024.

A.M. Olivarez, Department of Earth Sciences, University of Notre Dame, Notre Dame, IN 46556.

(Received: December 5, 1991: accepted: February 7, 1992.) 